\title{
THE COMPLEMENTARY EFFECTS OF EMPATHY AND NONVERBAL COMMUNICATION TRAINING ON PERSUASION CAPABILITIES
}

\author{
Robin T. Peterson, Ph.D. \\ James M. Leonhardt, Ph.D. \\ New Mexico State University
}

\begin{abstract}
This paper investigates the possible complementary effects that training in empathy and nonverbal communication may have on persuasion capabilities. The narrative considers implications from the literature and describes an exploratory study in which students, in a managerial setting, were trained in empathy and nonverbal communication. Subsequent evaluations of these students by faculty evaluators and the students themselves provide preliminary evidence that training in empathy, on the one hand, and nonverbal communication on the other can be effective, but concurrent training in both of these is superior to concentration in only one. This is the first research report which deals with such concurrent training and its impact on persuasion effectiveness in business communication.
\end{abstract}

Keywords: empathy, nonverbal communication, persuasion, training, business communication

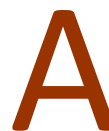
chievement in organizations often requires selling one's ideas to others, convincing others that particular courses of action have positive or negative consequences, and leading others to actions that will be beneficial to the employer. Persuasive ability can be used to convince company employees and others outside the firm, such as customers, to accept suggestions and proposals. On the other hand, if an organization member is ineffective in persuading others, he or she may be unsuccessful at large (Hodler, Loertscher, \& Rohner, 2014). Research is needed that identifies methods capable of enhancing the persuasive abilities of marketing and other personnel. The objective of this paper is to consider the possible complementary effects that training in both empathy and nonverbal communication may have on persuasion effectiveness in business communication.

This objective is unique and fills a knowledge gap by offering preliminary evidence to support the notion that training in both of these areas may be superior to training in only one-the two may be complements to one another. In particular, in an exploratory study, MBA students $(N=192)$ were assigned to one of four training conditions in which they received training in nonverbal communication, empathy, nonverbal communication and empathy, or in general presentation skills. Faculty evaluators 
then assessed the students in terms of their persuasive capabilities, and the students also provided feedback on the perceived value of their training. Overall, we find support for the notion that training in either nonverbal communication or empathy is effective; however, training that includes both of these elements is more effective than either alone. Such results have important implications for both business instructors and practicing managers and trainers.

\section{BACKGROUND}

A combination of instruction in both nonverbal communication and empathy may be more useful than training in only one of the two. The literature has not reported on studies of the effectiveness of training in nonverbal communication techniques and empathy in persuading others to accept managerial proposals. In this study, we consider the efficacy of combining training in both fields to produce improved persuasion effects. We begin by consulting relevant literature on the possible effects of nonverbal communication and empathy training on persuasion. We then consider the possible effects of a combined training program.

\section{Nonverbal Communication}

Nonverbal communication or "body language" can be described simply as silent messages or messages without words. It encompasses actions involving posture, facial expressions, the distance between communicators, arm movements, hand movements, placement of the legs and feet, handshakes, and other related behaviors (Brinke, MacDonald, Porter, \& O'Connor, 2012; Puccinelli, Motyka, \& Grewal, 2010). The literature furnishes support for the usefulness of nonverbal communication as a device for conveying meaning, thoughts, attitudes, and perceptions. For instance, the ability to discern and determine what a person is saying nonverbally can be as important as the dialogue that transpires (Anderson, 2001; Gupta, 2013). In addition, it has been suggested that approximately $65 \%$ to $90 \%$ of every conversation is interpreted through this avenue (Warfield, 2001).

Nonetheless many managers may be unskilled in its practice (Warfield, 2002). Further, managers who depend primarily on verbal speech efforts to express their thoughts with subordinates, peers, superiors, and representatives of other organizations may be (perhaps unwittingly) disregarding a potentially advantageous communications channel (Haibe, 2012). For instance, research suggests that nonverbal communication techniques may allow managers to more effectively convey their thoughts and feelings (Arvind, 2009; Weisbuch \& Nalini, 2009), enhance their leadership and credibility (Weisbuch \& Nalini, 2008), develop rapport and trust (Wood, 2006), and build stronger alliances between individuals (Bedi, 2006). Such observations suggest that training in nonverbal communication may enhance one's persuasion capabilities.

\section{Training in Empathy}

Empathy may also affect persuasiveness. Empathy refers to the ability to mentally position oneself in the place of others. In particular, empathy is depicted as possessing four constituents: 1) the empathizer understands the target's situation and emotions, 2) the target experiences one or more emotions, 3) the empathizer perceives a similarity between what the target is experiencing and something the 
empathizer has experienced previously, and 4) the empathizer is concerned with the target's well-being (Hakansson \& Montgomery, 2003). Essentially, empathy is an attitudinal framework, but it also involves various techniques and practices. Those who employ this concept try to see the world from the eyes of the person with whom they are communicating. They attempt to imagine what the most important needs of this person are and why he or she has these needs. In short, they take a genuine interest in that individual.

Empathy has been found to be a useful communication and persuasion device in a variety of applications, including sales, counseling, and consulting work (Molka-Danielsen, Carter, \& Creelman, 2009; Wong \& Sohal, 2002). In particular, there is evidence that empathy has a significant role in contributing to effective communication and persuasion in business (Oceja et al., 2014). For example, empathy on the part of spokespersons has been linked to their ability to overcome resistance from audience members (Lijiang, 2010). In addition, empathy may enhance the ability of product designers to satisfy their consumers (Kouprie \& Visser, 2009), and has also been linked to important determinants of customer loyalty (Marandi \& Harris, 2010). This discussion offers support for the notion that training in empathy may enhance one's persuasion capabilities.

\section{Training in both Nonverbal Communication and Empathy}

There is also some indication that, for managers, a combination of nonverbal communication accompanied by a mental state characterized by empathy may be a more effective persuasion agency than either of these practices alone. Currently, one of the most popular explanations for empathy is perceived similarity: we feel sympathy, compassion, and empathy to the degree that we perceive others to be like us (Coulter \& Coulter, 2003; Gill, Flaschner \& Shachar, 2006). Indeed, empathy has been found to be a stronger predictor of communication effectiveness when the communicator and the recipient perceive themselves to be members of similar groups (Gianelli, Scorolli, \& Borghi, 2013; Persson, Laaksolahti, \& Lonnqvist, 2001; Sturmer, Snyder, \& Omato, 2005). On the other hand, an emphasis on nonverbal communication in the absence of empathy may result in mechanistic manipulation of the face, body, arms, etc. in a self-seeking, rigid, and opportunistic manner that ignores the needs and preferences of the intended communications recipient and which may be interpreted as manipulative. For instance, research suggests that if receivers of messages perceive that the sender is intentionally utilizing nonverbal communication as a persuasion device, this may cast doubt on the sender's character and behavior (Mongrain \& Vettese, 2003).

Such research suggests that when communicators engage in successful nonverbal communication they may be creating the impression on the part of the prospect that the two are both members of the same or similar reference groups, since their behavior and appearance is similar. Indeed, many nonverbal communication techniques, such as mirroring the overt behavior of the communications recipient, recommend that communicators emulate the recipients' body language. In other words, an attempt is made to achieve observed similarity. This discussion supports the notion that nonverbal communication and empathy may operate in tandem and reinforce the effects of one another. This possibility is explored in following study. 


\section{EXPLORATORY STUDY}

An exploratory study was conducted to gain insight on the possible benefit that training in both nonverbal communication and empathy might have on the persuasion capabilities of students in a managerial setting. The study involved MBA students who received training in various combinations of nonverbal communication and empathy. The students then prepared and presented a case study to faculty evaluators who rated the students' persuasion capabilities. In addition, using self-reports, the students rated how valuable their training was in helping them prepare and present the case. In particular, this study set out to supply preliminary answers to the following research questions: (1) Will either nonverbal communication or empathy training result in higher persuasion capabilities and higher perceptions of training value than will training that does not include these elements? (2) Will training that includes both nonverbal communication and empathy result in higher persuasion capabilities and higher perceptions of training value than will training that includes only one of these elements?

\section{Method}

A total of 192 MBA students enrolled in one of six marketing management classes at a large southwestern university participated in the study. In each class, 32 students were randomly assigned to one of four training conditions in which they received training in one of the following: nonverbal communication, empathy, nonverbal communication and empathy, or general presentation skills, which served as our control condition. The nonverbal communication training taught students about each of the five major nonverbal communication channels, including body angle, face, arms, hands, and legs (Schwebel \& Schwebel, 2002). The empathy training taught students about self-awareness, including their cognitive and affective similarity with others (Smith, 2006). The nonverbal communication and empathy training taught students about the nonverbal communication channels and self-awareness of their cognitive and affective similarities with others. The general presentation skills training served as the control condition. In this condition, students learned about the mental, physical, and emotional preparation needed to make a successful presentation. Importantly, this condition did not include specific training in nonverbal communication or empathy.

After receiving their condition-specific training, the students received a case study on the Callaway Golf Company. The students were told that the objective of this exercise was to prepare and present an analysis of the case that would persuade their audience to accept their recommendations on what the Callaway Golf Company should do to overcome their major problems and take advantage of available opportunities. In each class, the students worked in teams of eight from the same training condition. Each of these teams then presented their analysis of the case to a faculty evaluator. The faculty evaluators $(N=6)$ were all members of the College of Business graduate faculty and had read and made their own analyses of the case prior to the student presentations. The faculty evaluators were not informed as to the objective of the study; rather, they were requested to hear and evaluate the presentations as a means of assessing the value of the instruction in case analysis that was being used in the marketing department.

The faculty evaluators rated each presentation using three items that served to measure the cognitive, behavioral, and affective dimensions of persuasion capabilities. In particular, the faculty indicated the 
degree to which they understood the recommendations $(1=$ full misunderstanding of the recommendations, 7 = full understanding of the recommendations), the extent to which they accepted the recommendations ( $1=$ full rejection of the recommendations, $7=$ full acceptance of the recommendations), and the degree to which they enjoyed the presentations ( $1=$ fully disliked the presentation, 7 = fully enjoyed the presentation). In addition, after the students had completed their presentations, but before they had received their presentation evaluations, they were asked to selfreport on the perceived value of their training using four items that have been used to assess the value of particular pedagogies (Peterson, 1995). Specifically, the students rated how well their training had prepared them to prepare and present the case $(1=$ did not prepare me very well, $7=$ did prepare me very well), how much they had learned from their training ( $1=$ very little, $7=$ very much), how much practical value their training had in preparing them for future job success ( $1=$ very little, $7=$ very much), and the extent that their training motivated them to achieve in management $(1=$ very little, $7=$ very much).

\section{Observations}

Table 1 presents a summary of the faculty evaluations of the presentations. Each of the six faculty members evaluated a total of four presentations, one from each training condition. This resulted in a limited number of evaluations, too small to make confident statistical comparisons between the training conditions (Chou, 1975).

Table 1

Summary of the presentation ratings by faculty evaluators $(N=6)$ by training condition.

\begin{tabular}{|c|c|c|c|c|}
\hline $\begin{array}{l}\text { Training } \\
\text { Condition }\end{array}$ & $\begin{array}{c}\text { Understood } \\
\text { Recommendations }\end{array}$ & $\begin{array}{c}\text { Accepted } \\
\text { Recommendations }\end{array}$ & $\begin{array}{c}\text { Enjoyed } \\
\text { Presentations }\end{array}$ & $\begin{array}{l}\text { Persuasive } \\
\text { Capability* }\end{array}$ \\
\hline & Mean (SD) & Mean (SD) & Mean (SD) & Mean (SD) \\
\hline $\begin{array}{l}\text { Nonverbal } \\
\text { Communication }\end{array}$ & $5.4(.49)$ & $3.6(.42)$ & $4.9(.47)$ & $4.6(.46)$ \\
\hline Empathy & $5.2(.56)$ & $3.9(.47)$ & $4.8(.42)$ & $4.6(.48)$ \\
\hline $\begin{array}{l}\text { Nonverbal } \\
\text { Communication } \\
\text { and Empathy }\end{array}$ & $6.0(.37)$ & $5.7(.44)$ & $5.8(.29)$ & $5.8(.37)$ \\
\hline Control & $4.7(.66)$ & $3.2(.42)$ & $4.4(.32)$ & $4.1(.47)$ \\
\hline
\end{tabular}

Note. ${ }^{*}$ The persuasive capability measure is the average of the preceding three items.

Despite this limitation, Figure 1 allows us to observe that training in either nonverbal communication or empathy seems to have been associated with higher persuasive capabilities than was training that did not include either of these elements (i.e., the control condition). Further, we can observe that training in both of these elements seems to have been associated with higher persuasive capabilities than was training in either of these elements alone. 


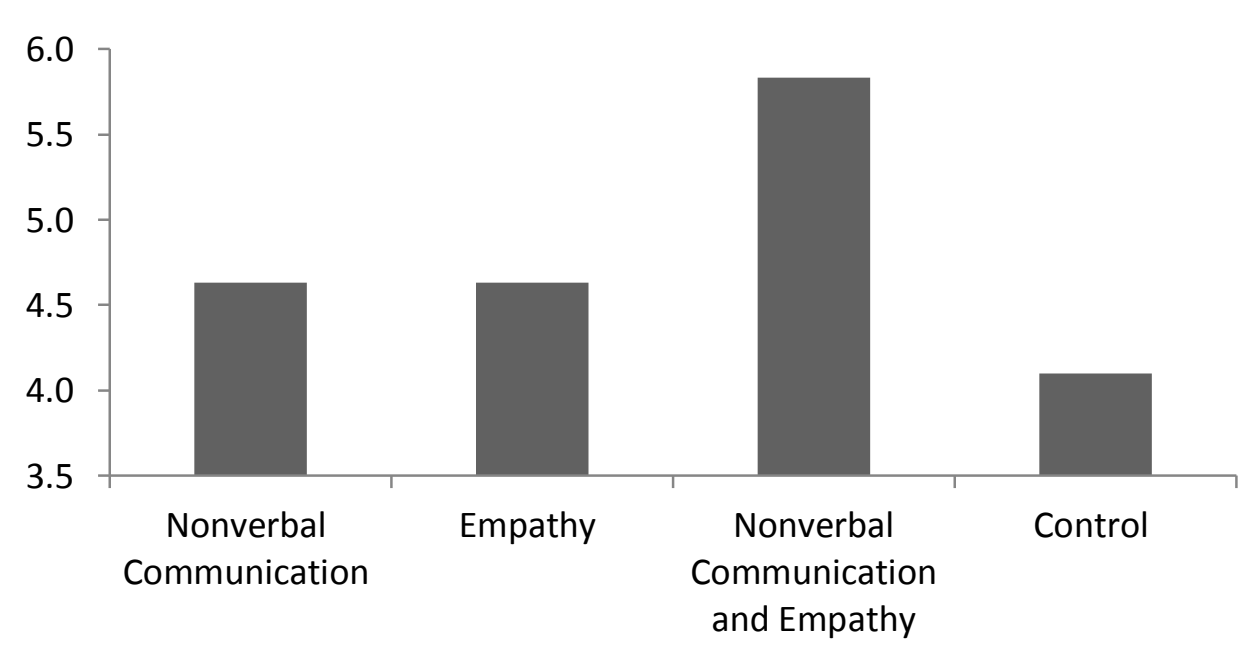

Training Condition

Figure 1. Average rating by faculty evaluators $(N=6)$ on the persuasive capabilities of students from each training condition.

In addition, Table 2 provides a summary of the students' self-reports on the perceived value of their training. For this measure, the sample size $(N=192)$ was sufficient to make statistical comparisons between the training conditions. In particular, an analysis of variance (ANOVA) and independent samples $t$-tests were appropriate for this between-subjects design that included 48 students in each of the four conditions. A measure of perceived value (the last column in Table 2) was created by taking the average of the four items used to assess how valuable the students had felt their training had been.

A one-way ANOVA with four levels, corresponding to each training condition, indicated that training condition had a significant effect on perceived training value $(F(3,188)=10.29, p<.001)$. Follow-up independent samples $t$-tests (at the alpha $=.05$ level) indicated that students who received training only in nonverbal communication perceived their training as more valuable $(M=5.2, S D=1.1)$ than did students in the control condition who had received training only in general presentation skills, the control condition $(M=4.5, S D=1.6, t(94)=2.50, p<.001)$. Similarly, students who received training only in empathy perceived their training as more valuable $(M=5.2, S D=1.3)$ than did students in the control condition $(t(94)=2.50, p<.001)$. Further, students who received training in both nonverbal communication and empathy perceived their training as more valuable $(M=6.1, S D=1.6)$ than students who had received training only in nonverbal communication $(t(94)=3.21, p<.01)$, or only in empathy $(t(94)=3.02, p<.01)$. Figure 2 provides an illustration of these comparisons. 
Table 2

Summary of the self-report ratings by students $(N=192 ; n=48$ per condition) on the perceived value of their training.

\begin{tabular}{|c|c|c|c|c|c|}
\hline $\begin{array}{l}\text { Training } \\
\text { Condition }\end{array}$ & $\begin{array}{l}\text { How effective } \\
\text { was this } \\
\text { training in } \\
\text { preparing me } \\
\text { for the } \\
\text { presentation? }\end{array}$ & $\begin{array}{l}\text { How much } \\
\text { did I learn } \\
\text { from this } \\
\text { training? }\end{array}$ & $\begin{array}{l}\text { What was } \\
\text { the practical } \\
\text { value of this } \\
\text { training for } \\
\text { my future } \\
\text { job success? }\end{array}$ & $\begin{array}{l}\text { What was the } \\
\text { value of this } \\
\text { training in } \\
\text { motivating me } \\
\text { to achieve in } \\
\text { management? }\end{array}$ & $\begin{array}{c}\text { Perceived } \\
\text { Value* }\end{array}$ \\
\hline & Mean (SD) & Mean (SD) & Mean (SD) & Mean (SD) & Mean (SD) \\
\hline $\begin{array}{l}\text { Nonverbal } \\
\text { Communi- } \\
\text { cation }\end{array}$ & $5.8(.9)$ & $5.3(1.5)$ & $4.9(.8)$ & $4.7(1.1)$ & $5.2(1.1)$ \\
\hline Empathy & $5.6(1.0)$ & $5.3(1.3)$ & $5.1(1.7)$ & $4.6(1.0)$ & $5.2(1.3)$ \\
\hline $\begin{array}{l}\text { Nonverbal } \\
\text { Communi- } \\
\text { cation and } \\
\text { Empathy }\end{array}$ & $6.2(1.4)$ & $6.3(1.1)$ & $6.3(1.8)$ & $5.5(2.1)$ & $6.1(1.6)$ \\
\hline Control & $5.0(1.2)$ & 4.8 (1.7) & $4.0(1.0)$ & $4.2(2.3)$ & 4.5 (1.6) \\
\hline
\end{tabular}

Note. ${ }^{*}$ The perceived value measure is the average of the preceding four items.

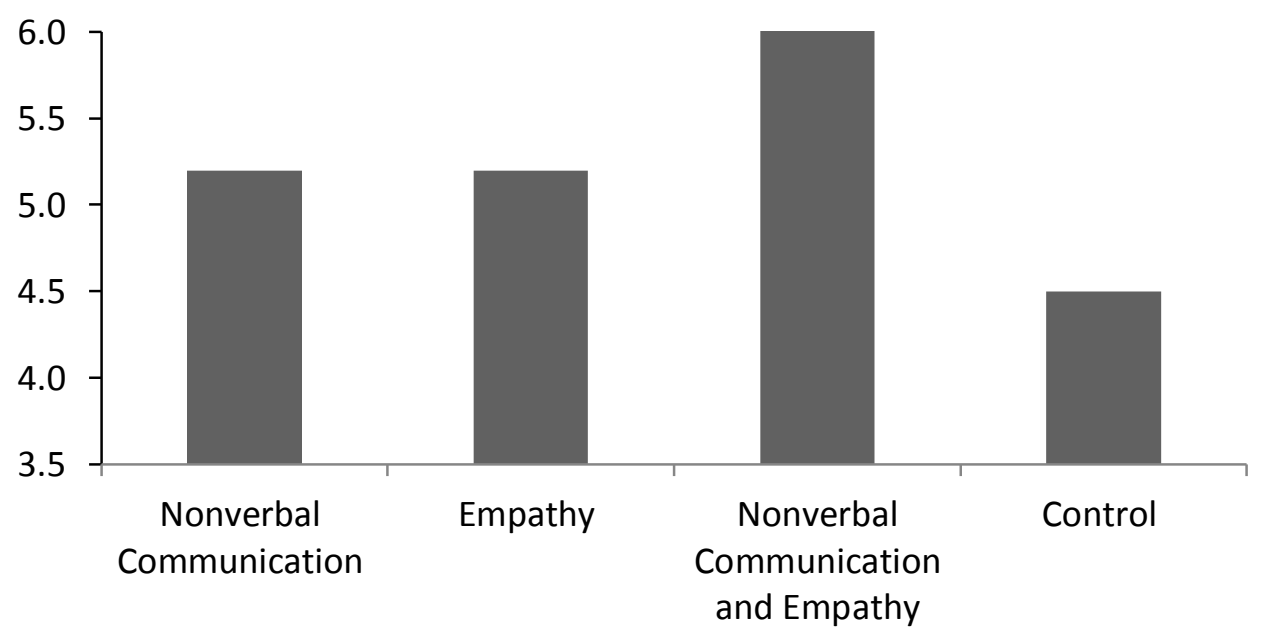

Training Condition

Figure 2. Average self-reporting rating by students ( $N=192 ; n=48$ per condition) from each training condition) on the perceived value of their training. 


\section{DISCUSSION}

These simple observations suggest affirmative answers to our research questions. That is, training in either nonverbal communication or empathy may be more affective at increasing persuasive capabilities than training that lacks these elements. Further, training that includes both nonverbal communication and empathy may result in higher persuasive capabilities than does training in either of these elements alone. Likewise, students may perceive training that involves either nonverbal communication or empathy as more valuable than training that lacks these elements. And students may perceive training that involves both of these elements as more valuable than training which only includes one of these elements. Overall, while our study was exploratory in nature, these observations suggest the potential contributions of training in both nonverbal communication and empathy as avenues for enhancing the proficiency and success of persuading others to pursue a course of action.

\section{CONCLUSION}

Previous studies reported in the literature have examined the effects of nonverbal communication and empathy, but have not examined the two as they operate in tandem-as possible complements. As evidenced by our review of the literature and our exploratory study, educators may do well to consider joint training as a possible avenue of approach. Much of the work of practicing managers involves convincing others, often group members, personnel in other company departments, subordinates, superiors, and employees of other firms, to accept recommendations forged by a team or an individual (Fulfer, 2001). Thus, techniques which enhance the persuasive capabilities of current and future managers, e.g., MBA and other students, have potential value for the firm and its employees. In particular, instructors of MBA classes who desire to further the persuasive communication capabilities of their students may find that these two topics deserve consideration for inclusion in the course content.

\section{Limitations and Opportunities}

This paper has certain limitations, but also creates several opportunities for additional research. For instance, individual firms may vary in the degree to which nonverbal communication and empathy are incorporated as components of their training programs, depending upon their needs and available resources. Indeed, it would be useful to ascertain if the training described in this paper will produce long-term effects on trainees. For instance, longitudinal follow-up measures of the effects of the training may assist in ascertaining if the skills learned in the classroom are transferred to real-life business activities. In addition, it may be important to consider training in reading and interpreting the body language presented by those whom they are attempting to convince (Anderson, 2001). Skill in this function may be useful as a feedback mechanism to the manager that desires to discern the perceptions, attitudes, interests, desires, and motivations of their communication target (Fletcher, 2000).

The case analysts in the study were students enrolled in MBA classes in one university setting, and they were "selling" a set of recommendations which did not have a monetary price to or a benefit for the faculty evaluators. Hence, the setting was removed from "real world" applications, where cost and 
benefit considerations are of considerable importance, and the results of the study cannot be generalized to all presentation efforts, including those which are common in industry. Future research could examine the effect of monetary and other benefits to the targets of the persuasive efforts. In a similar vein, the makeup of the experimental and control groups could have differed in such a way that their personal background, experience, and education confounded the results. The authors elected to assign students to the groups in a random manner in an attempt to minimize possible confounding from background sources. Future research in the field could assess the impact of training in nonverbal communication and empathy on other student and non-student populations. Efforts could be made to examine the characteristics of experimental and control groups, in order to identify and possibly eliminate confounding due to sampling error.

The study also employed the use of self-reports by the students. Some researchers may perceive selfreporting as a somewhat imprecise source of inputs; however, this method is widely employed in academic research and has been tested for reliability and validity. For example, it has been utilized to gather insights on consumer's emotional reactions to advertising (Moore, 2007), reports by managers (Hansen, Gam \& Romstad, 2007), individuals' reactions to stressors (Goffin \& Gellaty, 2001), managerial information retrieval (Greisdorf, 2003), and student sport participation (Yin \& Moore, 2004). In addition, various inquiries have provided evidence as to the value of self-reporting and in some cases have found it to be more accurate than other methods such as personal interviewing (Jensen, Eenberg, \& Mikkelsen, 2000; Morrell \& Arnold, 2007; Wilkins, et al., 2007 ).

Finally, it is important to consider that the observations reported in this paper apply to cultural norms existing in the United States and might not be applicable to other countries or even to some highly unique U.S. subcultures. Nonverbal behaviors are often culturally unique in meaning; that is, they may carry a particular view or understanding in one culture and a different one in another culture (Foster \& Afzania, 2005). In the Netherlands, for example, handshakes that are of short duration are likely to be perceived positively, but the opposite is the case in Italy (Clayton, 2003). Research is needed that considers how nonverbal communication and empathy may affect persuasion in cultures in which the elements of nonverbal communication may differ from those in the United States.

\section{REFERENCES}

Anderson, K. (2001). What you can say without speaking. Journal of Property Management, 66(5), 12-17.

Arvind, R. (2009). Gauging the effectiveness of your communication role. Strategic Communication Management, 13(2), 10-II.

Bedi, R. P. (2006). Concept mapping the client's perspective on counseling alliance formation. Journal of Counseling Psychology, 53(1), 26-35.

Brinke, L., MacDonald, S., Porter, S., \& O'Connor, B. (2012). Crocodile tears: facial, verbal and body language behaviors associated with genuine and fabricated remorse. Law \& Human Behavior, 36(1), 51-59.

Chou, Y. (1975). Statistical analysis with business and economic applications. New York, NY: Holt, Rinehart, \& Winston. 
Clayton, T. (2003). Body language at work. New York, NY: Barnes \& Noble.

Coulter, K. S., \& Coulter, R. A. (2003). The effects of industry knowledge on the development of trust in service relationships. International Journal of Research in Marketing, 20(1), 31-43.

Fletcher, W. (2000). Let your body do the talking. Management Today, 27(2), 23-31.

Foster, J., \& Afzania, M. R. (2005). International assessment of judged symbol comprehensibility. International Journal of Psychology, 40(1), 169-175.

Fulfer, M. (2001). Nonverbal communication: How to read what's plain as the nose-or eyelid-or chin-on their faces. Journal of Organizational Excellence, 20(2), 19-27.

Gianelli, C., Scorolli, C., \& Borghi, A. (2013). Acting in perspective: The role of body and language as social tools. Psychological Research, 77(1), 40-52.

Gill, A. S., Flaschner, A. B., \& Shachar, M. (2006). Factors that affect the trust of business clients in their banks. International Journal of Bank Marketing, 24(6), 384-405.

Goffin, R. D., \& Gellanty, I. R. (2001). Social support, group consensus, and stressor-strain relationships: social context matters. Journal of Organizational Behavior, 22(4), 437-451.

Greisdorf, H., (2003). Relevance thresholds: A multi-stage predictive model of how users evaluate information. Information Processing \& Management, 39(3), 403-427.

Gupta, N. (2013). Effective body language in organizations. Journal of Soft Skills, 7(1), 35-44.

Haibe, D. (2012). Who's there? Differences in the features of telephone and face-to-face conferences. Journal of Business Communication, 49(1), 48-73.

Hakansson, J., \& Montgomery, H. (2003). Empathy as an interpersonal phenomenon. Journal of Social \& Personal Relationships, 20(3), 267-284.

Hansen, L. G., \& Romstad, E. (2007). Non-point-source regulation-a self-reporting mechanism. Ecological Economics, 62 (4), 529-537.

Hodler, R., Loertscher, S., \& Rohner, D. (2014). Persuasion, binary choice, and the costs of dishonesty. Economics Letters, 12 (2), 195-198.

Jensen, L.K., Eenberg, W., \& Mikkelsen, S. (2000). Validity of self-reporting and video recording for measuring knee-straining work. Ergonomics, 43(3), 310-316.

Kouprie, M., \& Visser, F. S. (2009). A framework for empathy in design: Stepping into and out of the user's life. Journal of Engineering Design, 20(5), 437-448.

Lijiang, S. (2010). Mitigating psychological reactance: The role of message induced empathy in persuasion. Human Communication Research, 36(3), 397-422.

Marandi, E., \& Harris, J. (2010). The impact of perceived service provider empathy on customer loyalty: Some observations from the health and fitness sector. Managing Leisure, 15(3), 214-227.

Molka-Danielsen, J., Carter, B. W., \& Creelman, A. (2009). Empathy in virtual learning environments. International Journal of Networking \& Virtual Organizations, 6(2), 123-139. 
Mongrain, M., \& Vettese, L. C. (2003). Conflict over emotional expression: implications for interpersonal communication. Personality \& Social Psychology Bulletin, 29(4), 545-556.

Moore, D. J. (2007). Emotion as a mediator of the influence of gender on advertising effectiveness: Gender differences in online self-reports. Basic \& Applied Social Psychology, 29(3), 203-211.

Morrell, K., \& Arnold, J. (2007). Look after they leap: Illustrating the value of retrospective reports in employee turnover. International Journal of Human Resources Management, 18(9), 1683-1699.

Oceja, L., Heerdink, M., Stocks, E. L., Ambrona, T., Lopez-Perez, B., \& Salgado, S. (2014). Empathy, awareness of others and action: how feeling empathy for one-among others motivates helping others. Basic \& Applied Social Psychology, 36(2), 111-124.

Persson, P., Laaksolahti, J., \& Lonqvist, P. (2001). Understanding socially intelligent agents-a multilayered phenomenon. IEEE Transactions on Systems, Man, \& Cybernetics, 31(5), 349-361.

Peterson, R. T. (1995). Life history study for the personal selling class. Marketing Education Review, 5(3), 11-19.

Puccinelli, N. M., Motyka, S., \& Grewal, D. (2010). Can you trust a customer's expression? Insights into nonverbal communication in the retail context. Psychology \& Marketing, 27(10), 964-988.

Schwebel, D. C., \& Schwebel, M. (2002). Teaching nonverbal communication. College Teaching, 50(3), 88-92.

Smith, A. (2006). Cognitive empathy and emotional empathy in human behavior and evolution. Psychological Record, 56(1), 3-21.

Sturmer, S., Snyder, M., \& Omoto, A. M. (2005). Prosocial emotions and helping: The moderating role of group memberships. Journal of Personality \& Social Psychology, 88(3), 532-546.

Warfield, A. (2001). Do you speak body language? Training and Development, 55(4), 60-81.

Warfield, A. (2002). Your body speaks volumes, but do you know what it is saying? Business Credit, 104 (2), 20-21.

Weisbuch, M., \& Nalini, A. (2008). Affective divergence: automatic responses to others' emotions depend on group membership. Journal of Personality \& Social Psychology, 95(5), 1063-1079.

Weisbuch, M., \& Nalini, A. (2009). Unspoken cultural influence: Exposure to and influence of nonverbal bias. Journal of Personality \& Social Psychology, 96(6), 1104-1119.

Wilkins, J.R., Crawford, J. M., Stallones, L., Koechin, K. M., Shen, L., Hayes, J., \& Bean, T. L. (2007). Using participant event monitoring in a cohort study of unintentional injuries among children and adolescents. American Journal of Public Health, 97(2), 283-290.

Wong, A., \& Sohal, A. (2002). Customers' perspectives on service quality and relationship quality in retail encounters. Managing Service Quality, 12(6), 424-433.

Wood, J. A. (2006). NLP revisited: Nonverbal communications and signals of trustworthiness. Journal of Personal Selling and Sales Management, 26(2), 197-204. 
Yin, Z., \& Moore, J. B. (2004). Re-examining the role of interscholastic sport participation in education. Psychological Reports, 94(3), 1447-1454.

\section{ABOUT THE AUTHORS}

Robin T. Peterson, Ph.D. (ropeters@nmsu.edu) is the Robin T. Peterson Endowed Chair in Marketing in the College of Business at New Mexico State University. He is the author and co-author of a number of journal articles and books including Marketing Concepts and Decision Making. He is a past president of the Academy of Marketing Science and the Association of Small Business and Entrepreneurship. He teaches courses in personal selling and marketing management. Please address correspondence to Robin T. Peterson, Department of Marketing, New Mexico State University, MSC 5280, PO Box 30001, Las Cruces, NM, 88003-8001. Phone: (575) 646-5748.

James M. Leonhardt, Ph.D. (jleonhar@nmsu.edu) is Assistant Professor of Marketing in the College of Business at New Mexico State University. His research is in the area of consumer behavior and social media. He teaches courses in internet and social media marketing. Please address correspondence to James M. Leonhardt, Department of Marketing, New Mexico State University, MSC 5280, PO Box 30001, Las Cruces, NM, 88003-8001. Phone: (575) 646-3486. 